\title{
Comparative Analysis of Performance between Two Phase Ejector with Accomulator and COS Split Air- Conditioning Dual Evaporator
}

\author{
Made Ery Arsana ${ }^{1}$, \\ I G N Wijaya Kusuma², Made Sucipta ${ }^{3}$ \\ Study Program of Doctoral Engineering Science \\ Udayana University, \\ Denpasar, Indonesia \\ 1eryarsana@pnb.ac.id
}

\author{
I Nyoman Suamir ${ }^{4}$ \\ Study Program of Mechanical Engineering \\ Bali State Polytechnic \\ Bali, Indonesia \\ Denpasar, Indonesia
}

\begin{abstract}
The purpose of this study is to increase the coefficient of performance (COP) of the split air conditioner (SAC) by reducing the compressor work and increasing cooling capacity which can be achieved with a two phase ejector as an expansion device with novel design dual evaporator temperature. Numerical methods implementing mathematical model developed in EES software. The EES modelling is used to simulate the influence of key parameters of the ejector to overall system performance of the split air conditioner (SAC). Such key parameters include entrainment ratio involving mass flow rate of secondary and primary flow in the ejector and pressure lift ratio comprising pressure in suction and diffuser sections. Performance analysis of the SAC system with a two-phase ejector is performed to reach ASHRAE Standard requirement of a constant COP for SAC application minimum of 3.5. The SAC system simulated is charged with $\mathrm{R}-290$ as the fluid medium of cooling capacity at least $4000 \mathrm{BTU} / \mathrm{hr}$ based on numerical model simulation results the ejector is then produced and installed in a modified SAC system. Experimental test system is set to experimentally investigate and comparation analisys the actual performance of the ejector and its effect to the novel design dual evaporator temperature COS-SAC system performance. The SAC system performance with ejector is also found to be significantly improved is about $35 \%$ greater than those of conventional expansion device system.
\end{abstract}

Keywords--COP, Split type air conditioner, two-phase ejector

\section{INTRODUCTION}

Air conditioners are generally used to condition the air so as to achieve a standard of comfort where temperature and humidity correspond to the required level of comfort. Currently its use is increasingly widespread not only for office buildings and hotels but also has become the completeness of household needs. So the cost of using electrical energy for air conditioner (Air Conditioning) for home and industrial needs has increased significantly. In the literature it is stated that the proportion of electrical energy used by the refrigeration system in a building and the hotel industry using electrical energy is $65 \%$ of the $70 \%$ energy use as a whole. This requires attention in the effort of energy conservation especially electrical energy [1].

The split air conditioner as we know it uses a vapor compression cycle technology that works using a vapor compression cycle that still uses a capillary pipe as its expansion valve. Existing theories about the installation of expansion valves (Capillary Pipes, TXV Valves, etc.) in the refrigeration system are expansion valves functioned for the process of regulating the mass flow of the refrigerant as well as reducing the pressure from the condenser pressure to the evaporator pressure occurring under the conditions of the constant enthalpy process. One of the thermodynamic disadvantages of the vapor compression cycle is the isenthalpic expansion process that occurs in the expansion valve. While the isenthalpic process will reduce the cooling capacity in the evaporator due to energy losses in the throttling process in the expansion process. Capillary pipes are also known to have weaknesses due to friction of the refrigerant flow along the pipe wall as well as changes in velocity along the capillary pipe will cause considerable energy loss.

To overcome such energy losses isentropic process required. Ejectors can be used to generate constant entropy in the throttling process. Some researchers who have tried the appropriate ejector device on the cooling system also state an increase in COP from the system such as: Single-phase ejectors in modified systems utilized for air conditioning and heat pumping applications resulting in $7 \% \mathrm{COP}$ improvement up to $9 \%$ [2]. The concept of using a two-phase ejector to reduce losses due to the process throttling process in the cooling system was first offered [3]. In addition, the two-phase flow ejector has no moving parts, low cost, simple construction and low maintenance requirements that make it a promising system modification [4], [5] Furthermore, the subject of research into applied research that is currently popular among researchers is by replacing the expansion valve of the capillary pipe with ejector device. Kornhauser. A. A. et al. [6] in different studies using ejector expansion as an expansion device in the cooling system and by using R-12 refrigerant, R-134a concluded the 
same by comparing them to conventional vapor compression refrigeration systems it is known that there is an increase in COP values ranging from $3.8 \%$ to $21 \%$. Chunnanond $\mathrm{K}$. et al. [7] call the refrigeration system, the use of two-phase flow ejector as an expansion tool called ejector expansion refrigeration system (EERS). Use of a two-phase flow ejector instead of the conventional expansion device is one of the efficient techniques to improve the system performance not only by recover the expansion process loss by generating isentropic expansion process but also by increase the system cooling capacity and decrease the compressor power[8]. While the two-phase flow categories into two types based on the position of motive nozzle ie; constant pressure ejector and constant area ejector [9]. The ejector, which is grouped into a constant-pressure ejector, is a ejector with a motive nozzle whose exit plane is located in the suction nozzle before to the constant area ejector where as the ejector whose outlet field of the motive nozzle exit plane within a constant area ejector was categorized as a constant area projection obtained from the report [10], [11], [12]. At the same operating temperature using a constant area ejector COP and its EER is higher than of the system using a constant pressure ejector as reported [13]. Bilir and Ersoy [14] also report on theoretical studies using R134a. In off-design conditions, the system shows higher COP values than conventional systems and by using COP constant area ejector can be increased by $22.3 \%$ depending on operating conditions. The various studies on numerical analysis and experimental results show that using a two-phase ejector as an expansion device allows for the improvement of COP in the steam compression cooling cycle. Thermodynamic analysis showed that COP improvement was above $20 \%$, but no experimental method resulted in an increase of more than $10 \%$ [15]. This resulted in improved systems and effects of geometric ejector dimensions, such as the throat of the motive nozzle, the suction chamber, the constant area and the diffuser being an interesting research topic by the majority of researchers. The nozzle is designed according standard based on recommendations from the ASHRAE Handbook including the other dimensions, including the lengths of each section and the convergent and divergent angles [16]. According to the experimental results obtained [17], the improvement of COP when using a two-phase ejector as an expansion device on the $\mathrm{AC}$ bus system is $8 \%$.

The invention still has disadvantages and limitations which include the use of an accumulator fluid and gas separator where it is possible to inefficiency in the introduction of refrigerant sucked on the compressor so that the liquid refrigerant will be able to enter inhaled compressor and this causes damage to the compressor and the system will not run properly. A large dimension of the accumulator complicates the design if it is to be used on a split AC

This study focused on liquid and vapor refrigerant separator or accumulator, using a secondary evaporator to replace its function. The objective of the present paper is to present the performance test results of a novel design of ejector with dual evaporator temperatur and comparisson that is predicted to be applicable to split AC by replacing the accumulator function. Moreover, the performance comparison between them will be predicted the efficiency of the compressor and internal ejector efficiency.

\section{EJECTOR REFRIGERATION SYSTEM FOR AIR CONDITIONER}

\section{A. The COS-SAC with dual evaporator}

A schematic illustration of the COS-SAC and the corresponding $\mathrm{p}-\mathrm{h}$ diagrams is shown in Fig.1.a and 1.b. The same components of this system are the same as conventional compression systems, such as compressors, condensers, expansion devices and evaporators, incorporated a two-phase flow ejector and an additional evaporator are inserted to recover the expansion process losses and to increase the compressor suction pressure completed the COS-SAC system. The saturated vapor exits from primary evaporator (point 1) is sucked and compressed to a high pressure and temperature using the compressor. Then, the superheated vapor exits from the compressor (point 2) is condensed by transfer its heat to the surrounding in the condenser $\left(\mathrm{Q}_{\mathrm{c}}\right)$. The high pressure saturated liquid exits from condenser (point 3) and then separated in forms of liquid expanded in the expansion device (point 3-4), through primary flow ejector (point 3-7), respectively. The primary flow passed through ejector under high pressure and expands through the converging -diverging nozzle. Mixing of the primary and secondary flows takes place in the constant area ejector (state 5) and a liquid and vapor mixture at an intermediate pressure leaves the diffuser (point 6) of the ejector to the primary evaporator inlet, whereas the vapour circulates back through compressor (point 1-2). The refrigerant after expanded in the expansion device (point 4), goes into the secondary evaporator, and finally enters the ejector as a secondary flow.

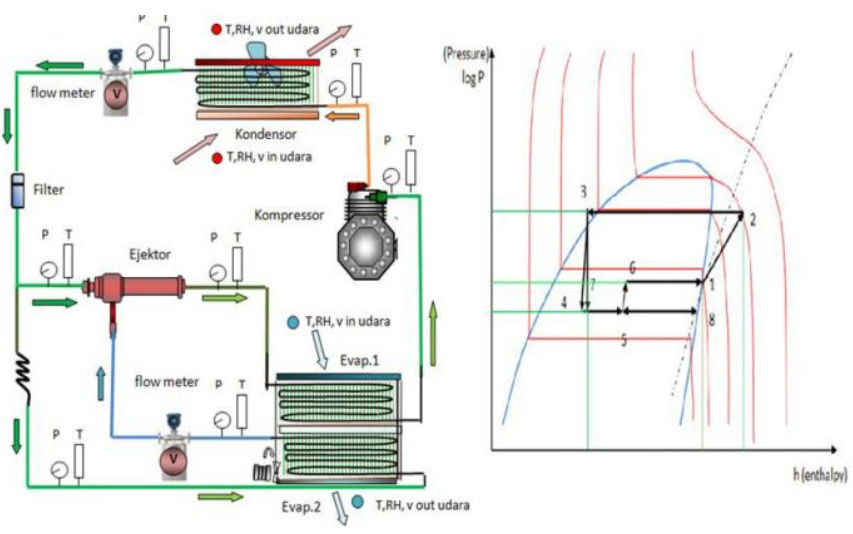

Fig. 1. Ejektor COS-SAC dual evaporator: a) schematic diagram b) p-h diagram

\section{B. The Ejector SAC with accumulator}

Refrigerant loops consist of vapor compression cycles with components: compressors, condensers, expansion valves and evaporation tools, and other accessory parts - oil separators (oil separators), liquid refrigerant containers (liquid receivers), filters / driers, glass / glass estimators (sight glass) and accumulator. The operating conditions of the equipment are conditioned the same as in the application of the type of air conditioning. In principle, the modifications of the standard 
refrigeration system are the addition of a two-phase ejector and a liquid-vapor separator.

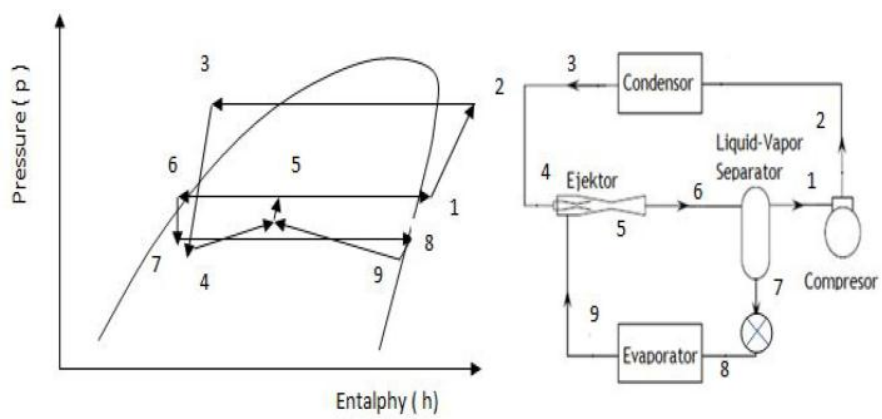

Fig. 2. Ejektor COS-SAC accumulator: a) schematic diagram b) p-h diagram

We have done a previous test of split ejector AC system with Figure 2 system which was designed based on [16] for the ejector dimension, and the test results on the system showed an increase in COP AC value of less than 10\%. Utilize of a standard ejector system in a split air conditioner using R-22 refrigerant equipped with engage of a liquid separator is large enough that it is not practical use. Thermodynamics simulation model [18], states that if the inefficiency that occurs about $15 \%$ of the liquid and vapor mass does not exit properly on the respective ports will be able to decrease the COP of the standard two phase ejector cycle under the valve expansion cycle. It is also noted that the ejector cycle with Condenser Outlet Split (COS) ejector cycle can achieve a COP improvement above $10 \%$ compared to conventional cycles.

\section{EXPERIMENTAL SET-UP}

The test was carried out by varying the R-22 and R290 refrigerants on the split AC prototype ejector system with the accumulator for reference data and on the system COS-SAC dual evaporator ejector evaporator system for further testing at ambient temperature around $28^{\circ} \mathrm{C} \pm 0.5^{\circ} \mathrm{C}$.

\section{A. Set-up Eksperimen}

See figure $3 \mathrm{a} \mathrm{AC}$ ejector system with accumulator and figure $3 \mathrm{~b}$ COS-SAC system for dual temperature evaporator. The same AC splits are first made for ejector testing with accumulator after the data is recorded as a data base and then the AC has changed its new design to a dual phase dual ejector temperature evaporator for the next test.
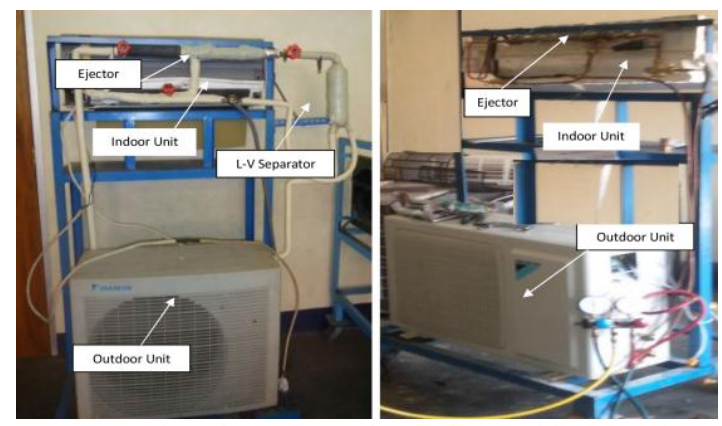

Fig. 3. a) Set-up eksperimental AC ejector sistem with accumulator b) AC ejector sistem with dual evaporator.
The test was carried out for 16 hours with 10 repetitions carried out to observe the presence of hysteresis and uncertainty in the study.

The test results are measurements of test parameters such as pressure data by installing the transducer pressure and temperature with a $\mathrm{K}$ type thermocouple, all recorded with acquisition data (Scan 7200 data). Power consumption is recorded with a power meter. The micro refrigeran flow meter on output condenser side and on the ejector inlet from the evaporator 2 is done to obtain the mass ratio $(\omega)$ entrainment ratio.
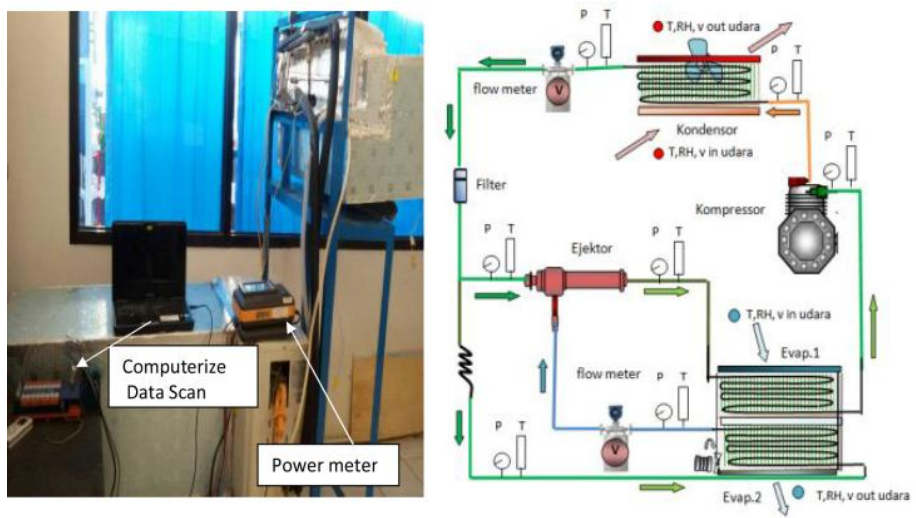

Fig. 4. Test equipment and measurement points

\section{B. Data analysis}

EES programs are used as data processors and program simulations are made where the formulation is developed by adjusting the calculation of each $(\omega)$ entrainment ratio for both systems. The formula refers to formulation (Ş. Ünal (2015). Graph display with the help of Excel programs.

\section{RESUlt AND DisCUSTION}

\section{A. Cooling capacity}

The cooling capacity of both systems see Figure 5 for systems with R-22 refrigerants the average value is 2035.95 Watts or 8660,723 BTU / hour and for R-290 is 3144.03 Watts or 10737.43 BTU / hour shows that the dual evaporator ejector system prototype is designed to Split AC works efficiently.

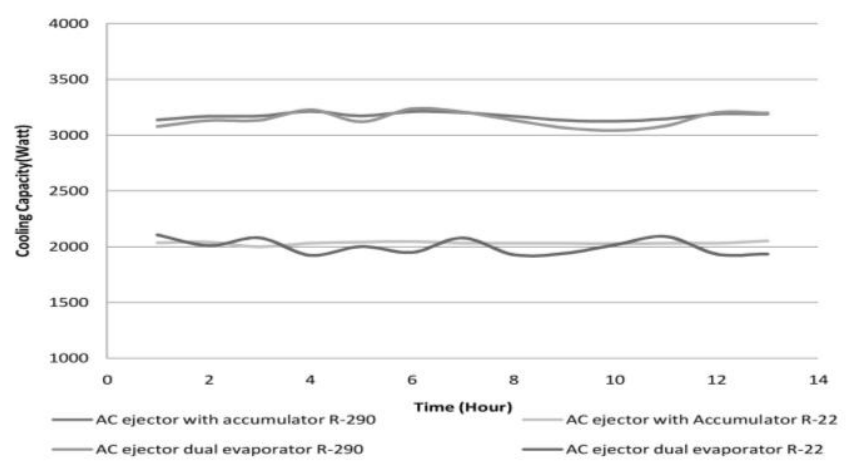

Fig. 5. Cooling capacity 


\section{B. Compressor input power}

Figure 6 shows the compressor input power usage which is 500 watts for 9000 BTU of cooling capacity / hour (1PK) so that when compared to standard AC for the same capacity where the compressor power usage is approximately 770 watts so there is a $35 \%$ savings potential from the power input from the compressor. As a result of these advantages, we have a compressor that has a smaller capacity to get cooling capacity that is greater than usual.

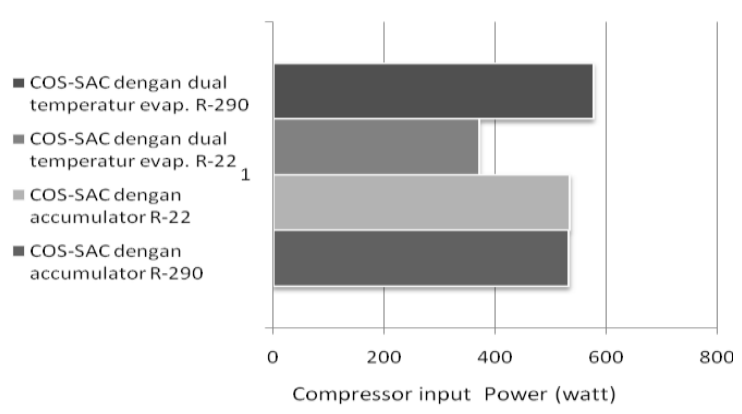

Fig. 6. Compressor input power

\section{COP sistem}

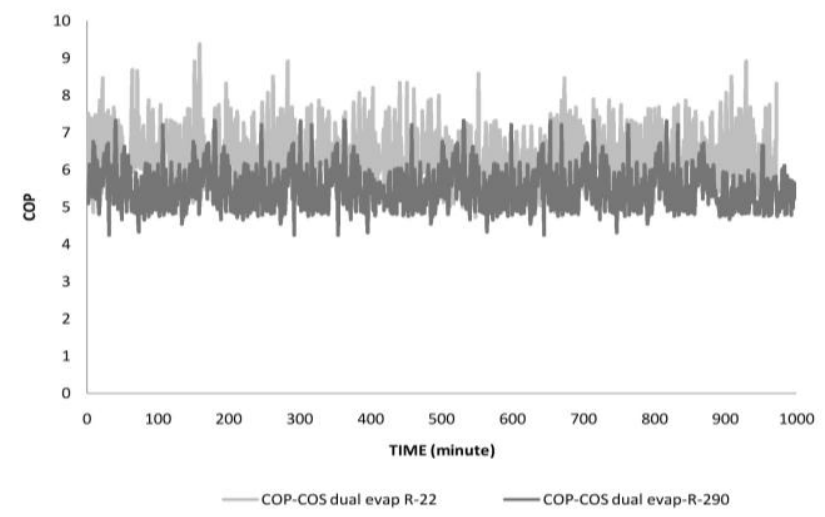

Fig. 7. COP system ejector COS with dual evaporator

See Figure 7. The results of experiments on a system with dual evaporator shows that the coefficient of performance (COP) of the system using R-22 Refrigerant is 5.80, the average value is better $5.1 \%$ of the COP system using R-290 with an average value of 5.52 .

Comparison of COP ratio of the ejector system with the accumulator see figure 8 . shows the reverse value of the system with R-290 Refrigerant average value of 5.50 and the system using R-22 is 5.10 so in using the system with the accumulator the R-290 refrigerant usage on the system is better $7,2 \%$.

When compared to COP from these systems, see figure 9. For dual AC evaporator, the ejector means the average COP 5.57 and 5.3 for a system that uses the accumulator. So that there is a potential increase in COP $4.9 \%$ Furthermore, when compared to the split system AC with the capillary tube as the expansion valve COP is 3.5 ASHRAE standard, the COP increase will be obtained $33.9 \%$ for accumulator systems and
$37.2 \%$ for systems with dual evaporator. This is in accordance with the statement Lawrence, et al. [18] was reported that there are several advantages theoretically the use of two phase Ejector COS multi evaporator system such as improve the distribution of refrigerant, reduce pressure drop and increase heat transfer coefficient of refrigerant. COS ejector cycles also have the advantage that in terms of oil return and theoretically COS ejector cycle COP will not be below when compared with the system using expansion valve.

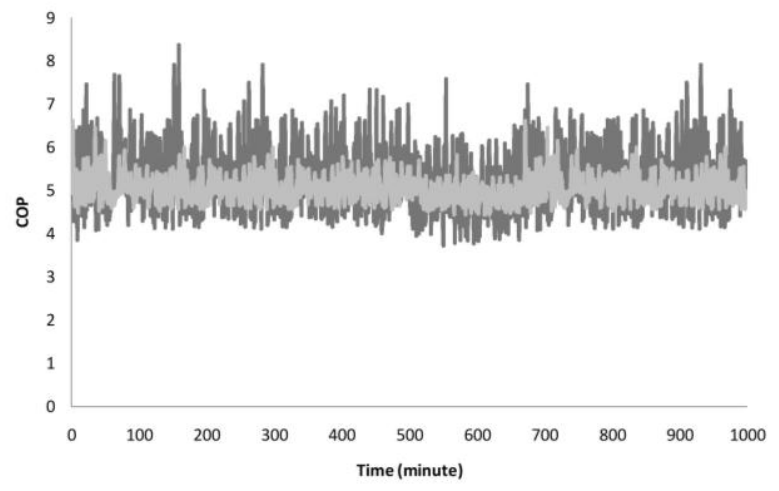

- COP-Accumulator-R290 - COP-Accumulator-R-22

Fig. 8. COP system ejector with accumulator

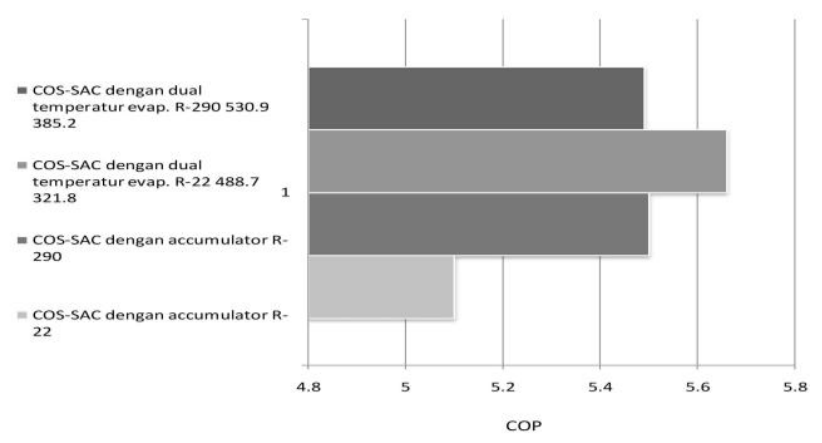

Fig. 9. Comparison of COP system values with the use of R-22 and R-290

\section{CONCLUSIONS}

Based on the results obtained from the study, it can be concluded that the use of a constant ejector area COS_SAC dual temperature evaporator and accumulator system are both prospective to be applied to split AC. A COP system that uses a COS_SAC dual temperature evaporator system has an average value of 5.57 and 5.3 when using an accumulator system thus the increase in COP was $4.9 \%$. Compared to power usage in compressors, this ejector system produces around $5.2 \%$ power savings for R-290 and $34.7 \%$ for R-22.

\section{ACKNOWLEDGMENT}

The authors acknowledge the financial support received from the Higher Education Directorate General of the Ministry of Research, Technology and Higher Education of the Republic of Indonesia. 


\section{REFERENCES}

[1] B. Kencana, I. Agustina, R. Panjaitan, and T. Sulistiyanto, "Panduan Praktis Penghematan Energi di Hotel,” p. 110, 2015.

[2] P. Menegay and A. A. Kornhauser, "Improvements to the ejector expansion refrigeration cycle," Energy Convers. Eng. Conf. 1996. IECEC 96., Proc. 31st Intersoc., vol. 2, pp. 702-706 vol.2, 1996.

[3] N. H. Gay, "USA Patent. Dec. 15, 1931.," 1931.

[4] S. A. Tirmizi, O. K. Siddiqui, P. Gandhidasan, and S. M. Zubair, "Performance analysis of an ejector cooling system with a conventional chilled water system," Appl. Therm. Eng., vol. 66, no. 1-2, pp. 113-121, 2014.

[5] K. Śmierciew, J. Gagan, D. Butrymowicz, and J. Karwacki, "Experimental investigations of solar driven ejector air-conditioning system," Energy Build., vol. 80, pp. 260-267, 2014.

[6] A. A. Kornhauser, "The Use Of An Ejector In A Geothermal Flash System," Proc. 25th Intersoc. Energy Convers. Eng. Conf., vol. 5, pp. 79-84, 1990.

[7] K. Chunnanond and S. Aphornratana, "Ejectors: Applications in refrigeration technology," Renew. Sustain. Energy Rev., vol. 8, no. 2, pp. 129-155, 2004.

[8] K. Sumeru, S. Sulaimon, H. Nasution, and F. N. Ani, "Numerical and experimental study of an ejector as an expansion device in split-type air conditioner for energy savings," Energy Build., vol. 79, no. October, pp. 98-105, 2014.

[9] J. Sarkar and S. Bhattacharyya, "Operating characteristics of transcritical $\mathrm{CO} 2$ heat pump for simultaneous water cooling and heating," Arch. Thermodyn., vol. 33, no. 4, pp. 23-40, 2012.

[10] J. Hu, J. Shi, Y. Liang, Z. Yang, and J. Chen, "Numerical and experimental investigation on nozzle parameters for R410A ejector air conditioning system," Int. J. Refrig., vol. 40, pp. 338-346, 2014.
[11] S. Elbel and P. Hrnjak, "Experimental validation of a prototype ejector designed to reduce throttling losses encountered in transcritical R744 system operation ' rimentale d' un e ' jecteur prototype conc Validation expe x u pour ' duire les pertes de laminage lors du fonctionne," vol. 31, pp. 411-422, 2008.

[12] S. Elbel, "Historical and present developments of ejector refrigeration systems with emphasis on transcritical carbon dioxide air-conditioning," Int. J. Refrig., vol. 34, no. 7, pp. 1545-1561, 2011.

[13] R. Yapici and H. K. Ersoy, "Performance characteristics of the ejector refrigeration system based on the constant area ejector flow model," Energy Convers. Manag., vol. 46, no. 18-19, pp. 3117-3135, 2005.

[14] H. K. Ersoy and N. Bilir, "The influence of ejector component efficiencies on performance of Ejector Expander Refrigeration Cycle and exergy analysis," Int. J. Exergy, vol. 7, no. 4, p. 425, 2010.

[15] K. Sumeru, H. Nasution, and F. N. Ani, "A review on two-phase ejector as an expansion device in vapor compression refrigeration cycle," Renew. Sustain. Energy Rev., vol. 16, no. 7, pp. 4927-4937, 2012.

[16] P. Chaiwongsa and S. Wongwises, "Effect of throat diameters of the ejector on the performance of the refrigeration cycle using a two-phase ejector as an expansion device," Int. J. Refrig., vol. 30, no. 4, pp. 601608, 2007.

[17] Ş. Ünal, "Determination of the ejector dimensions of a bus airconditioning system using analytical and numerical methods," Appl. Therm. Eng., vol. 90, pp. 110-119, 2015.

[18] N. Lawrence and S. Elbel, "Analytical and experimental investigation of two-phase ejector cycles using low-pressure refrigerants," Int. Refrig. Air Cond. Conf., pp. 1-11, 2012. 